\title{
FUNDAMENTOS DE LA SUBSIDIARIEDAD EN SIMONE WEIL: AUTORIDAD Y AUTONOMÍA
}

\author{
José Miguel Herrera y Rosario Athié ${ }^{1}$ \\ Universidad Panamericana, México.
}

Resumen: La condición por la que la filósofa francesa Simone Weil (1909-1943) redacta su célebre "Estudio para una declaración de las obligaciones respecto al ser humano" (1943) es que todo pueblo, gobierno y sociedad, la adopte como regla práctica de conducta, que sirva de inspiración a los más altos valores sociales que se encuentran inscritos en el corazón de los hombres. Fruto de esta exhortación, así como de su herencia intelectual y humana, nace nuestro deseo por transmitir la riqueza y la actualidad de su pensamiento, y de manera específica, de sus reflexiones sobre las condiciones de justicia social. El objetivo de este artículo es mostrar aquellas afirmaciones en sus escritos, que se refieren a las relaciones de autoridad y subordinación, que son la base para la definición del principio social de la subsidiariedad. En la primera parte, proponemos una introducción a este principio. Luego, expondremos sus dos principales elementos: autoridad y autonomía. Finalmente, haremos un repaso de los fundamentos de este principio a la luz de las reflexiones de Simone Weil.

Descriptores: Subsidiariedad $\cdot$ Libertad $\cdot$ Autoridad $\cdot$ Autonomía $\cdot$ Obligación $\cdot$ Necesidad

\begin{abstract}
The condition for which the French philosopher Simone Weil (1909-1943) writes her famous "Study for a declaration of obligations towards the human being" (1943) is that all people, government and society, adopt it as a practical rule of conduct, that serve as inspiration to the highest social values that are inscribed in the hearts of men. As a result of this exhortation, as well as his intellectual and human heritage, our desire is to transmit the richness and currency of her thought, and specifically his reflections on the conditions from which social justice has born. The aim of this article is to highlight those affirmations referring to the relations of authority and subordination, which are the basis for defining the social principle of subsidiarity. In the first part, we propose an introduction to this principle. Then, we will expose its two main elements: authority and autonomy. Finally, we will review the foundations of this principle in the light of Simone Weil's reflections.
\end{abstract}

Keywords: Subsidiarity $\cdot$ Freedom $\cdot$ Authority $\cdot$ Autonomy $\cdot$ Obligation $\cdot$ Necessity 


\section{INTRODUCCIÓN A LA SUBSIDIARIEDAD}

"Parecería que el hombre nace esclavo y que la servidumbre es su condición propia”. (Weil, 2007, p. 76). Con esta afirmación Simone Weil busca despertar en sus lectores la conciencia y la necesidad de reflexionar en torno a las condiciones de orden y de justicia social. Sin embargo, ¿qué realidad esconde esta afirmación? En contexto, se trata de una reflexión sobre las causas de la libertad y de la opresión social, y nosotros la hemos querido aprovechar para profundizar en el principio social de la subsidiariedad. Al parecer, entre los escritos de Simone Weil no aparece una consideración directa sobre la subsidiariedad; ${ }^{2}$ sin embargo, ella logra identificar y desarrollar dos de los principales elementos que componen este principio: la autoridad y la autonomía. Es importante también señalar que este artículo se basa en aquellos escritos en los que Weil plantea el problema de la libertad y de la autoridad. Queda pendiente una revisión más amplia de sus obras. El objetivo de este artículo es sólo despertar en los lectores el deseo por profundizar en el tema de la subsidiariedad.

Dicho principio social proporciona el orden de las relaciones entre la autoridad inmediata y las personas que están a su cargo, basado en la ayuda complementaria que ha de prestar a sus subalternos. La palabra subsidiariedad proviene de las palabras latinas subsidiarius y subsidium, que significan ayuda. Lo constituyen dos elementos que han de saberse mantener equilibradamente: autoridad y autonomía. Por su parte, la autoridad ha de prestar sólo la ayuda que sus subalternos requieran para que, por sí mismos, lleven a cabo las tareas que les corresponden. Por esta razón, no es posible hablar de subsidiariedad sin autoridad como tampoco sin autonomía.

Este principio es considerado como una continuación del principio de solidaridad, puesto que señala cómo debe ser brindada la ayuda, sin detrimento de la libre iniciativa de las personas, que se concretiza en la participación real, activa y natural de cada una en su medio vital y social. De manera que este principio se fundamenta en la jerarquía y en la libertad de cada persona, aspectos fundamentales en el pensamiento de Simone Weil. La autoridad debe reconocer no sólo la libertad individual de sus subordinados, sino también las necesidades que se originan como resultado de los desequilibrios que se generan día a día en la actividad de toda organización. El fin del principio de subsidiariedad no debe reducirse al bien material, incluso moral, ni con la ayuda que presta la autoridad, por más inmediata o provechosa que esta sea para el subordinado; el fin del principio es siempre recobrar o alcanzar la propia autonomía del subordinado dentro del ámbito de su relación con

\footnotetext{
${ }^{2}$ Emmanuel Gabellieri, quien ha estudiado largamente a Simone Weil, también identifica el principio de subsidiariedad en el pensamiento de la autora. Cf. Gabellieri (2018).
} 
la autoridad, de manera que cada individuo logre niveles más altos de participación, mediante la autoorganización y el autogobierno.

Si parece que el hombre nace esclavo, es debido a la influencia de su medio vital sobre él, que le condiciona de tal manera que incluso lo que puede llegar a la tentación de pensar que está privado de la plena iniciativa. El principio de subsidiariedad conserva y promueve el carácter pluralista del tejido social a través de un orden jerárquico bien articulado que asiste a sus subordinados creando las condiciones que permiten incrementar su participación y su plena iniciativa en el ámbito de su vida social, así como de reconocer en todo momento el ámbito de responsabilidad de la autoridad, su límite natural. Debe entenderse primeramente que la organización no es un instrumento dado a la autoridad para mandar, sino el ámbito por el que el ejercicio de mando sólo es eficaz en la medida en que coopera y aporta al bien común. Así, este principio se define como un método de cooperación que dispone que una necesidad debe ser atendida por la autoridad inmediata bajo un periodo determinado. Las estructuras de orden superior deben respetar, coordinar y fomentar el bien de las estructuras inferiores sin interferir innecesariamente en su actividad y su libertad legítima. No debe interferir en la vida interna, ni privarla de sus competencias, al contrario, debe promover las condiciones favorables que hagan posible su propia realización. Por ello, la autoridad puede suplir la actividad de sus miembros solo cuando ello resulta estrictamente necesario, es decir, cuando el individuo no pueda, por sí mismo, alcanzar el bien y cuando la acción de la autoridad se hace necesaria para salvaguardar equilibrio y la estabilidad del colectivo si éste se ve amenazado por la división, y en el tiempo en que dicha necesidad o amenaza persista. Es así como podemos afirmar que el principio de subsidiariedad es un método que respeta la subjetividad y la autonomía operativa de todos los individuos libremente asociados, con miras a un auténtico progreso colectivo.

\section{AUTORIDAD}

La autoridad es, al igual que la subsidiariedad, principio rector de la vida en sociedad. Es principio constitutivo del cuerpo político en tanto que forma parte de la comunidad (Nación), y a su vez posee un carácter instrumental en tanto que se subordina al Estado. Esto es lo que justifica en la autoridad su derecho a gobernar. De esta manera, toda autoridad, moral o política, se constituye en cuerpo y espíritu como condición material y moral para el fin común, y en consecuencia como mediador natural y libre del orden público y de la estabilidad social. Para Simone Weil, una sociedad o una organización que aspire a alcanzar grados de realización más elevados, debe ser en función del ejercicio efectivo de la autoridad desde lo más 
alto hasta lo más bajo de la jerarquía. Esto es así, dado que la autoridad, en razón de su constitución al orden público, es causa formal ${ }^{3}$ de la sociedad.

Para el filósofo francés Jacques Maritain, quien no gozaba de toda la estimación de Weil, ninguna sociedad tiene, en virtud de su propia naturaleza, el derecho de gobernar a los hombres. Todo derecho al poder, lo posee un hombre o una institución, en la medida en que constituye una parte del cuerpo político al servicio del bien común, pues "ha recibido ese derecho, dentro de ciertas limitaciones fijas, del pueblo que ejerce su derecho fundamental a gobernarse a sí mismo." (Maritain, 1984, p. 27). Este es quizás uno de los pocos temas en los que ambos filósofos coinciden, pues para ambos sería ilusorio concebir al pueblo gobernándose separadamente de sí mismo, o por encima de sí mismo: "La legitimidad está constituida por el libre consentimiento del pueblo respecto al conjunto de autoridades a las que está sometido." (Weil, 2000, p. 76). Hay que tener en cuenta que cuando se establece una sociedad es necesario un acto de asociación, es decir, un acto que reconozca el principio de libertad y mueva a la comunidad, en unidad de voluntades, a la transformación de un espacio común. Pero también es necesario un acto de sujeción, del reconocimiento de una autoridad dentro de un orden establecido que mueva al cuerpo político dentro de las coordenadas del bien común político. Del acto de sujeción deriva el carácter coercitivo de la autoridad, y la jerarquía constituye su límite en el ejercicio de su poder, su ámbito propio. Incluso en ausencia de autoridad, los individuos se orientan basados en formas de conocimiento vinculantes como puede ser el 'prestigio'. Una relación de autoridad puede, legítimamente, fundarse en el prestigio, pero corre el riesgo de asumir una opinión como verdad absoluta, o traducir la acción de la autoridad como una manifestación mística. El prestigio es para Weil, se diga lo que se diga, la causa mayor de conflictos entre los hombres que sólo priva de la atención a lo verdaderamente importante, pues no existe realmente elección entre todas las opiniones, y aunque se admitan todas, existe siempre el riesgo de traicionar la verdad, pero si tuviéramos que admitirlas - nos sugiere- debemos hacerlo "disponiéndolas verticalmente y colocándolas en los niveles adecuados, por ejemplo: azar, destino, Providencia." (Weil, 2007, p. 165). De la manera en que admitiríamos: vinculación, subordinación, sujeción.

Este vínculo ${ }^{4}$ entre la autoridad y el conjunto de los individuos no debe entenderse en términos de 'posesión', más bien, en tanto que es parte constitutiva del cuerpo social y por tanto del 'ser' del mismo. La existencia de un fin común, y

\footnotetext{
${ }^{3}$ Hugues Keraly en su Prefacio a la politica de Santo Tomas de Aquino (1976) explica los cuatro principios constitutivos de toda sociedad política, además de las causas operantes y permanentes del vínculo social.

${ }^{4}$ Sennett parte del concepto de vínculo para explicar el fenómeno de la autoridad. Sennett, Richard Authority. London School of Economics, London, 1993.
} 
por lo tanto de una tarea común, en razón de su eficiencia, requiere una organización y necesita de un principio-guía que dirija y coordine los esfuerzos con miras a dicho fin, que armonice la acción del conjunto. Este principio de unidad funcional es la autoridad. A este respecto, Simone Weil comprendió que la política, como toda actividad humana, es una acción orientada al bien y a la salud del cuerpo político, y por ende exige de nuestra parte el mayor cuidado y la mayor atención posible, y requiere por lo tanto de grados de consciencia más elevados y el acceso a modos de expresión más adecuados. Cuando se encarece la sujeción de la colectividad y la autoridad, es fácil reconocerse a la deriva, pues se encarece el vínculo entre el pensamiento y la realidad social, y es entonces cuando la libertad queda subordinada al capricho irracional de los acontecimientos, a modo de un esfuerzo inútil, pues la utilidad estaría en función de los medios y no del fin, resulta inútil por su desorientación al fin. La justa adecuación de los medios al fin colectivo depende de manera determinante de la autoridad. A tal efecto, una visión de Estado que subordina a los individuos al instrumento colectivo, difícilmente podrá aplicar el principio de subsidiariedad. Sería sencillamente imposible dado que este principio tiene un sentido descendente, es decir, que atiende la necesidad de cada individuo, y por lo tanto subordina el instrumento colectivo a las necesidades de los individuos. Es por esta razón que el principio de subsidiariedad lleva en su ejercicio a la descentralización del poder político. Al efecto, Simone Weil considera que las colectividades no deberían ser jamás tan extensas que sobrepasaran el alcance del espíritu humano, es decir, que lo propio de una colectividad es ser una comunidad de intereses. ¿Por qué? Porque lo propio del ser humano es la asociación, no la disociación. Así pues, debe reconocerse que al aumentar el número de individuos aumenta no sólo la necesidad material y moral de los ciudadanos, también el riesgo de su participación real, activa y consciente en el 'proyecto político' común. Cuando esto sucede, la autoridad puede ser el móvil más eficaz para subsanar las necesidades sociales, a condición de su correcto ejercicio en todos los niveles de la jerarquía social.

Tal como se afirmaba en la filosofía clásica, la autoridad es necesaria para la realización del bien común, para recorrer la distancia entre lo "necesario y lo bueno", 5 desafortunadamente, en la lucha por el progreso social, se trata menos de construir que de conquistar, decidir en función de la estrategia y no del equilibrio. Tal es el grado en que la autoridad condiciona el progreso social y la estabilidad de una Nación, que Simone Weil lo expresa de esta manera: "Cuando la ruptura de la legitimidad, el desarraigo, no es debida a la conquista, cuando se produce en algún país como consecuencia de un abuso de la autoridad legítima, lleva a pensar inevitablemente en la obsesiva idea de progreso." (Weil, 2003, p. 23).

\footnotetext{
${ }^{5}$ Platón, La República, Apartado VI: "La necesidad y el bien".
} 
Puede suceder, pero es sumamente perjudicial, que se conciba el progreso como poiesis, como realidad acabada, excluyendo así toda forma de autoridad, y en último término, toda forma de constitución política. El sentido clásico de progreso es modificación para mejor, el Estado es "una comunidad de iguales con el fin de vivir lo mejor posible", ${ }^{6} \mathrm{y}$ deja de ser comunidad o auténticamente política si la discrepancia entre sus miembros es tan grande que éstos dejan de tener la misma virtud, pues dejan de ser susceptibles de mejoras y se encuentran en un inevitable estado de cambio y agitación social.

Aquí es importante recordar que toda 'transformación' política no debe plantearse como un progreso global, único y definitivo, pues no tendría sentido preguntarse en qué medida implica una mejora y cuál es su precio a pagar en su realización. Toda transformación tiene un precio, y se trata de que ese precio no sea demasiado alto y no impida recibir la totalidad de los bienes materiales y morales del entorno del que forman parte las personas de manera natural, directa e inmediata. Cuando Simone Weil afirma que "la vida vende caro los progresos que nos obliga a hacer" (Weil, 2014, p. 45) lo hace para indicar que el bien que se persigue en el progreso debe ganarse y conquistarse con esfuerzo, pues todo bien verdadero comporta contradicción. El rechazo a una vida cómoda comporta una defensa contra los excesos del poder. Por su naturaleza, por su esencia, por definición, el poder constituye única y exclusivamente un medio, muy a pesar del interés de algunos por adjudicarle un valor absoluto: "es a la política lo que un piano es a la composición musical." (Weil, 1949, p. 276).

La autoridad es principio de unidad porque conlleva el reconocimiento social de un saber o de un poder; en ambos casos, se trata de un mismo saber o un mismo poder. Cuando se origina un reconocimiento oficial pero no social, in genere, la autoridad queda subordinada al poder; el saber se convierte en instrumento del poder y puede fracturar el vínculo entre autoridad y subordinado, pero lo que es más grave, hace aún más inaccesible el bien a los hombres. El saber de la autoridad es personalísimo, es decir, indelegable, íntimamente consustanciado al portador, $y$ en la medida en que un "saber personal" no es reconocido socialmente, queda reducido a pura ciencia, o a lo mucho, a un 'saber técnico'. Por ello, afirma Simone Weil que "la obediencia a un hombre cuya autoridad no está alumbrada con legitimidad es una pesadilla." (Weil, 2007, p. 203). La autoridad se degrada en un saber de dominio, pues su saber no es ya un fin en sí mismo, no sirve para la acción común, tan solo para su dominio y manipulación. Esta es la razón por la que no existe propiamente hablando una 'ciencia del poder'. El progreso no es una tendencia. En cambio, tenemos la tendencia a olvidar con extrema facilidad

\footnotetext{
${ }^{6}$ Aristóteles, Política VII, 8, 1328a36.
} 
que la política es un saber práctico, o al menos un saber prudencial. ${ }^{7} \mathrm{El}$ saber de autoridad requiere de un esfuerzo constante por prever lo que puede amenazar o alterar el orden social y político, porque la autoridad, en cuanto tal, carece de instrucción científica, y le es tan necesario adquirir un conocimiento prudencial, dada la velocidad y la magnitud de los acontecimientos, como alcanzar un grado de intuición vasto.

La autoridad, sea por potestad o por un saber, es un recurso moral delimitado a un ámbito propio de intervención. El ámbito de autoridad, o 'súper-espacio', es una realidad dinámica y creativa, es fuente de posibilidades para la acción común, de naturaleza ideal y relacional, pues se constituye no sólo como medio imprescindible para la satisfacción de necesidades, sino como garante de la dignidad y la realización humana y espiritual de la colectividad. Sin embargo, quien es autoridad en un ámbito determinado, se encuentra siempre -lo quiera o no-con la posibilidad de someter a los demás hombres, de oprimir a las almas con la fuerza de su mandato. Todo abuso en el ejercicio de la autoridad no es más que una forma del autoritarismo, así como la renuncia a ejercer la autoridad la causa de muchos totalitarismos, pues se abandona el ideal de justicia y con él, a los hombres. La desdicha tiene muchas caras, las más frecuentes suelen ser la opresión y el abandono, y ambas afectan directamente la libertad, y por ende la autonomía de los individuos: "la contradicción esencial de la condición humana es que el hombre está sometido a la fuerza y desea la justicia. Está sometido a la necesidad y desea el bien.” (Weil, 1957, p. 186).

La autoridad representa un equilibrio entre orden y libertad, una defensa frente a los excesos, a las extrapolaciones, para no subordinar el orden a la libertad, o la libertad al orden, en pro de intereses facciosos o absolutistas. Esto no quiere decir de ninguna manera que la autoridad establezca los límites, la autoridad no hace el orden, 'pone' en orden. La experiencia de la libertad es la experiencia de los límites, no se trata de avanzar lo más lejos o lo más rápido posible en una dirección, sino lo que es mucho más importante, de encontrar un cierto equilibrio óptimo entre lo que se es y lo que se dice ser, y que suele revelarse tras la interrogante ¿qué debemos hacer? Pero cuando se ignora la relación entre el esfuerzo colectivo y los límites inherentes a este, es una fuerza que aplasta al hombre al no encontrar resistencia moral capaz de contrarrestarla, y de la que no es inmune. Esto es lo que lleva a sustituir nuestra condición humana como servil, incapaz de autosuficiencia,

\footnotetext{
${ }^{7}$ A lo largo de la historia de las ideas políticas podemos identificar al menos dos tendencias, una la trazada por la filosofía política que busca la fundamentación de la política, la legitimidad del poder, la finalidad de la estructuración política de la vida entre otras reflexiones, por otro lado, tenemos la de la ciencia política, que tiene una visión más técnica de la política, que busca explicar el poder y la política no desde su legitimidad o finalidad última sino desde los criterios de realidad y eficacia, de modo que es propio de la filosofía, comprender el saber sobre lo político como un saber práctico, es decir auto-perfectivo de la misma polis. Cf. Villoro (1988).
} 
incapaz de pasar de un día al siguiente sin poder afrontar el sentimiento de su miseria humana, tan manipulable como la materia inerte. Pero, así como sucede con la materia, el fin de toda colectividad ha de ser la conservación del bien, y esta es, podríamos llamar, su primera obligación, pues toda obligación tiene como objeto una necesidad que remediar.

\section{AutONOMÍA}

Está claro que el sentimiento de necesidad en los hombres no manifiesta inmediatamente un deseo de satisfacción, demanda un deseo de conservación, que bien puede venir acompañado de un deseo de satisfacción, es lo que distingue entre la necesidad y el capricho: "un hombre al que se le arroja al agua en pleno océano, no debería dejarse hundir, a pesar de las pocas posibilidades que tuviera de encontrar la salvación, sino tendría que nadar hasta el agotamiento." (Weil, 2007, pág. 97). ¿Podría exigir la satisfacción de su derecho a conservar su vida? ¿A quién? Para Leo Strauss toda acción política se orienta hacia la conservación o hacia el cambio, cuando deseamos conservar un estado, tratamos de evitar el cambio hacia lo peor, y cuando deseamos realizar un cambio, intentamos siempre orientarnos hacia lo mejor. ${ }^{8}$ Este argumento se asemeja al de Weil, sin embargo, al colocar deseo de conservación y deseo de transformación en el mismo eje, establece oposición entre ambos y formaliza la lucha perenne entre 'conservadores y progresistas'. Simone Weil considera que esa visión sólo puede derivar en pasión colectiva y por lo tanto engendra mayor rivalidad y violencia en la sociedad, el germen de la desdicha.

Lo que es un hecho es que toda actividad humana, todo cuerpo político, busca conservar su forma humana, su 'mejor' forma social-humana posible. Esto significa que toda actividad se ve influenciada por la manera en que aprendemos lo mejor y lo peor, que a su vez implica una idea a priori del bien y del mal. La idea apriorística del bien y del mal sirven de guía a la aplicación del imperativo de Kant como órdenes que deben ser seguidas de manera incondicional, pero, independientemente de este sentimiento, afirma Simone Weil, son las condiciones materiales y morales ${ }^{9}$ las que van a orientar la actividad del hombre, principalmente aquellas de orden político, y no sólo la cuestión de un conocimiento del bien y del mal, que incluso, hoy, la experiencia confirma la costumbre moderna de negar la realidad de la oposición entre el bien y el mal. Lo que determina la correcta

\footnotetext{
${ }^{8}$ En la filosofía política de Strauss, la acción política se funda sobre la idea de conservación y cambio. Strauss (2006).

${ }^{9}$ Tocqueville, un siglo antes, coincide con Weil al afirmar reiteradamente que son dos lo más grandes males sociales; el primero se debe a la mala distribución de la riqueza intelectual de la población y el segundo a la desgracia de las clases pobres. Cf. Alexis de Tocqueville, Gustave de Beaumont (2005), p. 101.
} 
orientación del esfuerzo colectivo son las condiciones de la existencia misma, lo peor o lo mejor, en las condiciones materiales y morales en las que se vive y se sufre, y no sólo por una estimación subjetiva a priori. Esta disposición se origina de una necesidad real y concreta, no se deriva del ideal político. El problema estriba en que fácilmente hacemos del ideal político una virtud. "El ideal es tan irrealizable como el sueño, pero, a diferencia del sueño, se relaciona con la realidad." (Weil, 2007, p. 77) Por esta razón, las formulaciones de Simone Weil se dirigen a tratar de concebir una sociedad funcionando, no como un ideal realizable, sino con una tarea regulativa que se sostenga sobre la base de la obligación, y de una ciencia centrada en el mejoramiento de las condiciones sociales de equilibrio, sin desligarlo de la autoridad constituida, y sin detrimento de la propia libertad.

"La libertad es el poder de elección en el interior del margen que deja la coerción directa de las fuerzas de la naturaleza y la autoridad aceptada como legítima." (Weil, 2000, p. 68). La libertad, así como la autoridad, son necesarias, no sólo para el orden en las relaciones de mando y subordinación, sino por la necesidad, en tanto que sociedad, de conservar el fundamento de su propia génesis social. Si por azar o por mal gobierno se perdiera este origen, cada individuo se encontraría desposeído radicalmente de los medios de defensa, pues obedecería sólo en función del instrumento colectivo, el margen se reduciría dejando poca posibilidad de reacción, y lo que es infinitamente más grave, según lo entiende Weil, haría olvidar el valor de la vida y el sentido de la autoridad. La palabra autoridad viene del latín augeo que significa aumentar, crecer, dar plenitud a algo que no la tiene por sí mismo, en otras palabras, la autoridad 'promueve' el aumento, el auge en algo o en alguien. Así entonces, toda relación de subordinación está llamada a su plenitud y paradójicamente su origen es un sentimiento de contradicción, una especie de tensión que en toda subordinación se manifiesta como una resistencia casi natural de los de arriba a los esfuerzos que provienen de abajo: "El valor de un alma, se mide por su grado de resistencia a dicha prueba" (Weil, 2007, p. 144). La necesidad es por naturaleza contradicción, y la subordinación también, pues así como un sentimiento de contradicción puede ser insostenible para el individuo, la relación de subordinación es insostenible cuando el individuo no dispone soberanamente de sí mismo. Por lo tanto, la ayuda que la autoridad presta al subordinado debe facilitarle el acceso a una libertad menos imperfecta que su condición actual, pues lo mejor no es concebible sino por lo perfecto.

Así como la necesidad plantea el problema de la autoridad, así también nos coloca delante de la autonomía. Por su parte, la autonomía se define como auto-nomos, que significa darse a sí mismo sus leyes. Richard Sennett define la autonomía como un ser autosuficiente, y lo hace extraordinariamente al describir en una oración al hombre de nuestro tiempo: "nosotros pensamos que no necesitamos 
de los demás, sino que los demás nos necesitan." (Sennett, 1993, p. 31). Sobre esta afirmación, no cuestionamos la mutua necesidad de unos y otros, sino la idea de autonomía como un absoluto, de un individualismo radical. Considerar la sociedad como un todo ya dado y perfecto puede derivar en la creencia de que los individuos encuentran su propia realización sólo al recibir, y en consecuencia no habría más por hacer. Sería pura necedad afirmar, e ilusorio imaginar, que el todo es para la parte, y no así la parte para el todo. "Todo orden implica una autoridad legítima cuyas decisiones son obligatorias para quienes están sometidos a ese orden" (Weil, 2007, p. 268). Nos recuerda que todo acto de subordinación es, en último término, una conformación de las necesidades materiales y morales al Ideal social y político, es decir, del bien común político, de este se deriva su legitimidad. La obligatoriedad no nace del mandato de la autoridad, tampoco nace de la ley; la obligación nace de la determinación, que reside en la naturaleza de cada individuo, de realizar acciones que brotan de la propia y plena iniciativa, alcanzando su más pleno significado en su participación en el orden y el objetivo común, y su más plena expresividad al conformarse con los rasgos, valores y aspiraciones más profundos y constitutivos de la identidad que le es propia. En esto consiste la autonomía. La autoridad es condición necesaria, mas no suficiente, para la realización de la acción común, y para la acción común es necesario un orden que no imponga condiciones a la libertad de los individuos, y si la autoridad manda para mantener dicho orden, y puede legítimamente condicionar la actividad de la población, manteniendo permanentemente la posibilidad de actuar como fuerza cuando sea necesario, y sólo en la medida en que las necesidades de los individuos sean reaparadas o cubiertas. De manera que toda acción política requiere del reconocimiento de una autoridad legítima, reconocimiento que hace posible que converjan renuncia y afirmación; es lo que solemos llamar 'obediencia' ${ }^{10}$

Históricamente, ${ }^{11}$ toda relación de subordinación se ha expuesto a la luz del concepto de obediencia, y no pocas veces se ha establecido oposición entre la obediencia y la libertad. La evidencia nos dice que, ni la coerción, ni el argumento racional, ni los dos juntos, parecen poder dar cuenta de la coordinación de voluntades necesarias para la existencia de un orden social y político. Esta coordinación, o "equilibrio" en términos weilianos, podría sólo encontrarse en la distinción que ella hace del derecho y la obligación: "un derecho no es eficaz por sí mismo, sino por la obligación que le corresponde. El cumplimiento efectivo de un derecho no depende de quien lo posee, sino de los demás hombres, que se sienten obligados en algo

\footnotetext{
${ }^{10}$ Simone Weil solía asociar la obediencia al amor fati, el amor que representa la obediencia al orden del mundo, la aceptación del destino, una aceptación valiente, no pasiva como la resignación, y que no recae de manera absoluta en la autoridad.

${ }^{11}$ Sugerimos consultar el proceso histórico de las relaciones de subordinación y autoridad descrito por J. Raz (1990), p. 22.
} 
hacia él." (Weil, 2014, p. 22). Parafraseando a la filósofa francesa afirmamos que la autoridad es un concepto que de alguna manera se equipara al del derecho: la noción de autoridad está subordinada a la noción de obligación (obediencia) y por lo tanto es un concepto correlativo (referencial). Una autoridad no es eficaz por sí misma, sino por la obediencia que le comporta. Por lo tanto, no depende de quien posee autoridad, sino de los demás hombres que se sienten obligados hacia ella. No hay autoridad donde no hay acto libre de sujeción, donde no hay una elección deliberada de una forma de vida en común. Por ello, la obediencia sólo es posible bajo las condiciones de reconocimiento y consentimiento a una autoridad, de hecho y de derecho. Es una actividad fundada en el 'consentimiento', en una obediencia consciente, pues sólo donde hay consentimiento -afirma Weil- es posible hablar de libertad: "La legitimidad está constituida por el libre consentimiento del pueblo respecto al conjunto de autoridades a las que está sometido." (Weil, 2000, p. 76). De otra manera, sin el consentimiento, se corona a la Libertad, se concluye en una visión de la sociedad que busca su origen y su fin en la libertad más pura y genuina, pero no más incierta y desconocida para ella misma. Este esfuerzo moderno por salvaguardar a cualquier costo nuestra libertad, hace reproducir una visión de justicia como realización de libertad, pues se afirma y se constituye como un derecho fundamental y prioritario del Estado. Es lógico que los esfuerzos se dispongan y se orienten a la conservación de este bien sagrado, en que sólo bastaría con ir por la vida con los 'ojos vendados', ${ }^{12}$ cada uno tendría la obligación de hacerse de los bienes que más les plazca sean estos públicos o privados, poco importa.

Así como no hay autoridad donde no hay consentimiento mutuo, tampoco habría auténtica autonomía sin el asentimiento expreso a una voluntad. Sólo cuando dos voluntades convergen en un mismo punto, en unidad de miras, es posible hablar de un verdadero examen de lo que es bueno, justo y verdadero para ambas partes. Sólo así se asegura la reconciliación. Sin este mutuo consentimiento, todo argumento de autoridad pierde su fuerza y vitalidad porque puede dar entrada a la ambigüedad, a la mentira y finalmente a la desconfianza. Simone Weil estima en gran medida la confianza, de ella hablará en una de sus tantas cartas a Víctor Bernard en 1936, dice: "Cuando las órdenes confieren una responsabilidad a quien las ejecuta, implican una cierta confianza mutua entre el jefe y el subordinado (...). Este es un recurso moral que no se utiliza." (Weil, 2014, p. 181). Cuando hay confianza la subordinación es una cosa bella y honorable. De esta manera, el reconocimiento de la autoridad presupone una expresión del 'entendimiento' y un 'consentimiento' por parte del subordinado, y éste se obliga para actuar conforme a la voluntad y al argumento racional de la autoridad. La autoridad es una inteligencia desprovista

\footnotetext{
${ }^{12}$ Se hace referencia al concepto de "velo de ignorancias" de J. Rawls. Cf. Rawls (2010).
} 
de fuerza directamente imperativa, la fuerza de su mandato se la confiere el libre consentimiento y reconocimiento de sus subordinados.

\section{Fundamentos de Subsidiariedad En Simone Weil}

Hemos repasado los conceptos que subyacen en las reflexiones de Simone Weil entorno a la relación de subordinación, y que sirven de guía para explicar el principio social de subsidiariedad. Las ideas que ahora vamos a exponer se refieren más concretamente a las reflexiones hechas por la filósofa, donde establece las condiciones que deben darse para que las relaciones de subordinación conduzcan a una mayor cooperación entre los que mandan y los que obedecen, y una mayor atención a las necesidades y a las obligaciones para con los más vulnerables.

Estas reflexiones se ponen de manifiesto más claramente en sus últimos escritos en Londres y sus últimas cartas, y más concretamente en su "Estudio para una declaración de las obligaciones respecto al ser humano." (1943). En este escrito, Weil pone de manifiesto que la primera necesidad de los hombres es aquella que se deriva de su condición corpórea, es decir, la necesidad de alimento, de calor, de sueño, de higiene, de reposo, de ejercicio, de aire puro. En seguida, Weil hará mención de una serie de obligaciones, todas ellas, respecto a la condición espiritual y moral del hombre, las necesidades del alma humana. Lo que es importante destacar es que las tres primeras necesidades del alma se refieren a la autoridad y la autonomía: “(1) El alma humana tiene necesidad de igualdad y jerarquía. (2) El alma humana necesita obediencia consentida y libertad. (3) El alma humana necesita verdad y libertad de expresión" (Weil, 2000, p. 68). Privar el alma de autoridad, de libertad y de verdad sería verdaderamente un acto criminal y un verdadero atentado contra la dignidad de los hombres. Este hecho se verifica en que los conflictos más encarnizados y amenazadores de la historia y tiene como característica común, lo que constituye su verdadero peligro, es que 'no tienen objetivo definible', y sin objetivo, ¿cómo es posible la vida en sociedad? ¿Hasta dónde valdrá la pena llevar los esfuerzos? ¿Tendría sentido hablar de cooperación? Sea como fuere, el objetivo de Simone Weil es hacer, de esta declaración sobre las obligaciones para con los seres humanos, el canon de nuestro obrar, sea individual o colectivamente. Esto es posible sólo a través de un método de cooperación que reconozca las necesidades y las aspiraciones de los individuos, y sea capaz de traducirlos en modos y procedimientos prácticos, que se erijan como auténticas escuelas de derechos y obligaciones.

El segundo aspecto de la idea subsidiaria de Simone Weil se presenta concretamente en el ámbito del lenguaje. Para ella, la posibilidad de brindar una verdadera ayuda a los subordinados radica, primeramente, en poner en sus bocas las palabras que expresen solamente el bien, lo que sería verdaderamente un servicio 
de primer orden pues reduce la posibilidad de manipulación y fomenta una mayor capacidad de expresión y comunicación verbal. Es una manera de disminuir el riesgo de conflicto y sin eliminar el vínculo de subordinación, indispensable para hacer respirable la vida en sociedad. Existen palabras, afirma Simone Weil, "incapaces de pisar la tierra." (Weil, 2014, p. 52), y el mejor servicio que se puede hacer a los subordinados es aportar las palabras que expresen su realidad misma, palabras que, a través de las circunstancias exteriores, hagan perceptible las condiciones morales de las personas con el fin de que sepamos hacer una 'lectura' correcta de los demás. "Leemos, pero también somos leídos por otro." (Weil, 2007, p. 168). El error es caer en un diálogo de sordos en el que se obliga a alguien a que se lea a sí mismo como le leen los demás (colectivismo), y por otro lado obligar a los demás a que nos lean como nos leemos a nosotros mismos (individualismo). El "diálogo ideal"13 es justo lo contrario, es el tipo de diálogo que opta por la justicia y la verdad, como recuerda Sócrates en Gorgias 505e. En el fondo, afirma Weil, cada ser humano grita en silencio pidiendo ser leído de otra manera. Y, ¿cuál es la causa de una mala lectura? Para nuestra autora será la opinión pública y las pasiones, difícilmente superable en el marco de conformismo social que vive la sociedad moderna, "¿qué esperanza le queda a la inocencia cuando no se la reconoce?" (Weil, 2007, p. 168). Al parecer, sólo nos quedarían los 'beneficios imaginarios' que proporcionan energía para esfuerzos ilimitados. Los beneficios imaginarios son en gran medida recursos morales. Weil lo explica cuando afirma que un rey no puede pagar más que recompensas la mayor parte del tiempo imaginarias, si no se volvería insolvente: "a falta de la sonrisa de Luis XIV, nos fabricamos un dios que nos sonría, o aún más, nos alabamos nosotros mismos." (Weil, 2007, p. 60).

Hay que tener en cuenta que toda forma de recompensa supone una degradación de energía por el esfuerzo derivado del trabajo, por tanto, una recompensa puramente imaginaria es el equivalente exacto de lo que uno ha gastado, porque obtiene de manera exacta el valor de lo que se ha gastado, al contrario de las recompensas reales, que como tales, se hallan o por encima o por debajo. La imposibilidad de relacionar lo que se da con lo que se recibe, es para la filósofa francesa lo que ha ocasionado la pérdida del sentido del trabajo, más aún, del trabajo bien hecho. Este es sin duda un factor de estabilidad social: "Los hombres nos debemos lo que nos imaginamos que nos daremos. Condonar las deudas." (Weil, 2007, p. 60). No es un desprecio de lo material, es la reivindicación de la dimensión espiritual y moral como condición de auténtico progreso social. Un pequeño de 8 años que demanda alimento en un cruce de caminos tiene tanta necesidad de autoridad, como de alimento. Se requiere, por tanto, de hacer el inventario de

\footnotetext{
${ }^{13}$ Spaemann (2004), p. 162.
} 
nuestra civilización para preparar el futuro, separar lo que sirve al individuo de lo que dé armas a la sociedad contra él mismo. Así entonces, la idea subsidiaria de Simone Weil tiene como objeto el discernir lo imaginario de lo real a través del esfuerzo por dar realidad mediante la palabra, pues una sola palabra bien empleada y perfectamente comprendida es la mejor ayuda que podemos prestar a los demás.

Según Simone Weil, la cooperación tiene por objeto ampliar las posibilidades de la experiencia de cada individuo sobre la base de la libertad, esto es, sobre la base de la acción individual autónoma y crítica, y sobre la concepción de una ciencia centrada en el mejoramiento de las condiciones materiales y morales de los individuos. La subsidiariedad no tiene por objeto la sustitución del subordinado por la autoridad. Incluso en el ámbito del conocimiento, sustituir un saber por otro, sólo tiene sentido en la medida en que no excluye el anterior. Lo que la autoridad debe hacer muy bien es dar estímulos, no puede remplazar a su subordinado por el hecho mismo de que busca su propia autonomía. Para Simone Weil, el trabajo deviene en una especie de muerte cuando carece de estímulo, sería como actuar renunciando a los frutos de la acción, el pensamiento está obligado a pasar de un instante a otro sin poder agarrarse al pasado ni al futuro. Weil trae a colación al duque de Lauzun ${ }^{14}$ para explicar el valor de un estímulo y su eficacia al atender una necesidad moral. El duque prefería estar preso y ser capitán de mosqueteros, a estar libre y no serlo. Hemos de comprender, primeramente, que toda ayuda representa la acción más auténtica de conversión y de inversión en la vida del hombre, y por ello lo más valioso y lo más auténticamente humano. De manera que, la ayuda que presta la autoridad no es por así decirlo- para un fin determinado, sino por una necesidad, que significa trasladar fuera de uno los móviles de sus propias acciones. Es hacer algo, no por alguien, sino con alguien, incluso en la distancia, en donde cabe la posibilidad de 'no hacer nada', ese espacio es benéfico para ambos, y es un vínculo -en ocasiones- capaz de acortar todas las distancias que separan a las personas. Toda la ayuda que brinda la autoridad hace de él un intermediario "entre la tierra inculta y el campo labrado, entre los datos del problema y la solución, entre la página en blanco y el poema, entre el desdichado con hambre y el desdichado saciado." (Weil, 2007, p. 91).

Simone Weil destaca con firmeza el hecho de que la colectividad no piensa y, por ello, "la organización de la sociedad ideal debe apoyarse sobre los hombres considerados como individuos, en su esfuerzo consciente" (Weil, 2007, p. 148). De manera que, otro aspecto de la idea subsidiaria de la filósofa francesa nace de su

\footnotetext{
${ }^{14}$ Simone Weil se refiere a Antoine Nompar de Caumont, mariscal de Francia, conde y más tarde duque de Lauzun que estuvo a punto de casarse con la princesa de Orleans, la Grande Mademoiselle, como la llama Mme. De Sévigné en una de sus cartas, pero Luis XIV prohibió la boda en última instancia. No obstante, gozó del favor real, lo cual no le evitó probar por sí mismo la lobreguez de los calabozos de La Bastilla.
} 
ideal por dignificar el trabajo, inyectándole pensamiento, sin pretender hacer de la actividad del trabajador, compartimentos cerrados que por un lado, trabaja, y por otro, piensa. Se trata de la única vía de subsistencia de nuestra civilización, salvar la 'capacidad individual de pensar y actuar', pues el rigor del pensamiento se proyecta en el rigor de los actos. Para Weil, la sociedad menos 'mala' es aquella donde el común de los hombres se encuentra más a menudo en la obligación de pensar al actuar, dado que aumentan las posibilidades de control y de autonomía. Un ejemplo de estos esfuerzos lo encontramos en las universidades, pues hoy en día todas ellas buscan implementar nuevos modelos de organización que les lleven a aprovechar mejor sus recursos y a optimizar la gestión administrativa, sin perjuicio de la probidad intelectual y del servicio que presta a la sociedad. El riesgo se presenta cuando una institución o un individuo se limita a 'sobrevivir', se vuelve incapaz de distinguir entre pensamiento y acción, pues todos sus gestos están determinados por la 'tendencia' del mercado; la rige la eficacia, no la fecundidad. Las universidades son percibidas, por lo general, como auténticos mercados de la vanidad intelectual. Por esta razón, es preciso recordar que no es la experiencia la que se nutre de la producción, sino la producción la que se nutre de la experiencia, pues la vida intelectual es anterior a la producción. La fractura entre docencia e investigación, materializa en gran medida la gran preocupación de Simone Weil: la imposibilidad de conciliar pensamiento y acción. El divorcio entre el trabajo manual y el trabajo intelectual de inicios del siglo XX, que Weil vivió en carne propia, se ha instalado finalmente en el ámbito universitario. A pesar de ello, la fuerza y la grandeza de la vida universitaria no procede de sus recursos económicos o políticos, sino de lo que está inscrito en sus aulas: pensar con originalidad, con libertad y con energía creadora. Mientras sea fiel a esta tarea, tendremos en ella un aliado en el cultivo del saber y un remanso de libertad académica.

Weil encuentra en la autoridad la obligación de estimular el pensamiento, no de paralizarlo, de transmitirle el conocimiento necesario que lleve al subordinado a vencer los obstáculos derivados de su crecimiento y de ganar en método, en definitiva, alcanzar un mayor grado de autonomía. El principio de subsidiariedad, en consonancia con el ideal de cooperación metódica de Simone Weil, tiene su base en entender la autoridad como intermediario, por la ayuda que esta presta, fundamentada en un saber hacer, y que requiere del primer principio pedagógico de proximidad inmediata. Esta disposición de proximidad inmediata de la autoridad, delimitada por la esfera o ámbito de autoridad, es la condición de posibilidad para el efectivo ejercicio de la actividad colectiva. Se requiere de un método que permita concluir visiones de conjunto sobre los diversos niveles de la organización, o sobre los distintos estratos sociales. Esto no es una tarea fácil, como bien reconoce Weil: "Ninguna poesía que concierna al pueblo es auténtica si en ella no se encuentra el cansancio, y el hambre y la sed nacidos 
de ese cansancio." (Weil, 2007, p. 209). En todo sistema, los subordinados remiten instintivamente a la autoridad tanto sus sufrimientos como sus más altos ideales y deseos. Estos deseos, o tormentos, muchas veces se confunden con sus propios intereses particulares, pero por lo general chocan con la protesta irreprimible del ser humano a causa del abandono o el abuso de la autoridad. Hay que entender que toda autoridad se preocupa con razón de su autoridad. Esta atención en sí mismo es la principal, y quizá la única, causa de la pérdida de la visión de conjunto, y que es responsabilidad de la autoridad el evitar. Nos preguntamos entonces, ¿Cómo conservar la visión de conjunto? ¿Qué riqueza esconde la proximidad entre la autoridad y el subordinado? La autoridad debe atender a tres necesidades concretas de quienes están sujetos a ella, y ésta respresenta la cuarta idea subsidiaria en Simone Weil. Estas tres necesidades se dan en distintos grados en los subordinados, como padecimientos, y sólo es posible identificarlos en la medida en que la autoridad desarrolle una sensibilidad especial para identificarlos. Se trata del aburrimiento, la privación, y la humillación. (Weil, 2007, pp. 204, 207). Remediar estos males tan comunes en cualquier organización, conlleva, como hemos dicho, el deber de la autoridad de mantenerse cercano a quien están a su cargo, pues sólo así es posible identificar y remediar estos males, así como la levadura levanta la masa únicamente cuando se mezcla con ella, así la autoridad debe regular la distribución de competencias y de responsabilidades entre sus subordinados evitando cualquier manifestación de opresión que atente contra la plena iniciativa personal.

\section{CONCLUSIÓN}

Al profundizar en el principio social de la subsidiariedad a la luz del pensamiento de Simone Weil queda patente que esta propuesta está abierta a estudios ulteriores. Ofrece, así mismo, un programa para mejorar las relaciones de subordinación y autoridad en cualquier ámbito de la vida social. Como hemos analizado, el principio de subsidiariedad es un método de cooperación que tiene como elementos la autoridad y el subordinado, y tiene como objeto la autonomía del subordinado por medio del correcto ejercicio de la autoridad. Para nuestra filósofa, se requiere del compromiso de estar especialmente atentos a las necesidades de los seres humanos que dependen de alguna manera de nosotros. Es preciso, pues, que los gobernantes se persuadan de que mientras más perfectamente se realice el orden jerárquico, de acuerdo con los principios y valores fundamentales de la vida social, mayores serán la autoridad y la potencia social, más próspera y justas las instituciones y costumbres sociales. Para dar solución a los conflictos sociales que nos afligen, es necesario no perder de vista, poner nuestra atención, en que en cada individuo se encuentra lo más digno y lo más valioso de la realidad que -junto con el amor- es el pensamiento. 
Aristóteles. (1988). Política. Introducción, traducción y notas de Manuela García Valdés. Madrid: Gredos.

Gabellieri, E. (2018). Penser le travail avec Simone Weil. Versión digital: Nouvelle Cité Éditions.

Keraly, H. (1976). Prefacio a la política de Santo Tomas de Aquino. México: Editorial Tradición.

Maritain, J. (1984). El hombre y el estado. Buenos Aires: Club de Lectores.

Rawls, J. (2010). Sobre las libertades. Barcelona: Paidós.

Raz, J. (1990). Authority. New York: New York University Press.

Sennett, R. (1993). Authority. London: London School of Economics.

Spaemann, Robert. (2004). Ensayos filosóficos. Madrid: Ediciones Cristiandad.

Strauss, L. (2006). La ciudad y el hombre. México, D.F.: Katz Editores.

Tocqueville, A. y Beaumont, G. (2005). Del sistema penitenciario en Estados Unidos y su aplicación en Francia. Madrid: Editorial Tecnos.

Villoro, L. (1988:). "Ciencia política, Filosofía e ideología". Vuelta, 12, 137, pp. 18-22.

Weil, S. (1949). L’Enracinement. Paris: Éditions Gallimard.

Weil, S. (1957). Opresión y libertad. Buenos Aires: Editorial Sudamericana.

Weil, S. (2000). Escritos en Londres y últimas cartas. Madrid: Trotta.

Weil, S. (2003). El conocimiento sobrenatural. Madrid: Trotta.

Weil, S. (2007). Escritos históricos y políticos. Madrid: Trotta.

Weil, S. (2007). La gravedad y la gracia. Madrid: Trotta.

Weil, S. (2007). Reflexiones sobre las causas de la libertad y de la opresión social. Madrid: Trotta.

Weil, S. (2014). Echar raices. Madrid: Trotta.

Weil, S. (2014). La condición obrera. Madrid: Trotta.

Weil, S. (2014). La persona y lo sagrado. Barcelona: Los pequeños libros de la sabiduría. 